\title{
Comparative Evaluation of the Radiopacity of Bone Graft Materials used in Dentistry
}

\author{
${ }^{1}$ Emine S Kursun-Çakmak, ${ }^{2}$ Nihat Akbulut, ${ }^{3}$ Dogan D Öztas
}

\begin{abstract}
Introduction: Ample radiopacity in order to distinguish from the surrounding tissues is a desirable property of dental graft materials. A total of 15 bone graft materials' (BGMs) opacities were analyzed in this study.
\end{abstract}

Materials and methods: Graft materials were placed in the implant cavity $(5 \times 10 \mathrm{~mm})$ in cadaver's mandible respectively. Cavity was exposed by using periapical film and a dental $X$-ray machine at $70 \mathrm{kVp}$ and $8 \mathrm{~mA}$. The optical density of the radiographic images was measured with a transmission densitometer. One-way analysis of variance (ANOVA) was conducted for statistical analysis.

Results: Among the materials tested, the most radiolucent bone grafts were Grafton and Allogenix with a statistical significance of $p \geq 0.05$. 4Bone and Bego Oss exhibited the highest radiopacity with a statistical significance of $p \geq 0.05$. Inadequate radiopacity of the dental graft materials may lead to confusion among clinicians in the radiographical follow-up. Among 15 BGMs tested, only three had higher density than bone tissue.

Conclusion: The radiopacity of the BGM was found to be higher than bone at only three of them.

Keywords: Bone graft, Cadaver, Densitometry, Radiopacity.

How to cite this article: Kursun-Çakmak ES, Akbulut N, Öztas DD. Comparative Evaluation of the Radiopacity of Bone Graft Materials used in Dentistry. J Contemp Dent 2017;7(3):150-155.

\section{Source of support: Nil}

Conflict of interest: None

\section{INTRODUCTION}

Bone graft materials are frequently used in orthopedics, periodontics, and in oral and maxillofacial surgery with effective clinical outcomes. ${ }^{1}$ The BGMs that are presently

\footnotetext{
${ }^{1,2}$ Associate Professor, ${ }^{3}$ Professor

${ }^{1}$ Department of Oral and Maxillofacial Radiology, Ministry of Health, Public Hospitals Agency of Turkey, Ankara, Turkey

${ }^{2}$ Department of Oral and Maxillofacial Surgery, Faculty of Dentistry, Gaziosmanpasa University, Tokat, Turkey

${ }^{3}$ Department of Prosthodontic Dentistry, Faculty of Dentistry Ankara University, Ankara, Turkey

Corresponding Author: Emine S Kursun-Çakmak, Associate Professor, Department of Oral and Maxillofacial Radiology Ministry of Health, Public Hospitals Agency of Turkey, Ankara Turkey, Phone: +905364563921, e-mail: sebnemkursun@ yahoo.com.tr
}

used in dental clinics are autogenous bones, allogeneic bones, xenogeneic bones, and alloplastic materials. ${ }^{2}$ Although autogenous bone grafts are thought to be the gold standard for bone grafting, it has some disadvantages, such as the formation of a second surgical region, causing morbidity in the donor region, and only being able to take a limited amount. ${ }^{3}$ The need for an allogeneic source of bone arose from the need for increased donor material and the problems associated with autogenous bone procurement mentioned above. ${ }^{4}$ Allogenic bone is usually processed as a freeze-dried graft or as a demineralized bone matrix (DBM). The former is usually placed with autogenous grafts due to the lack of osteogenic and osteoinductive capabilities. ${ }^{1}$ Xenografts are more available in greater supply than allografts and have larger sizes. Most of the xenografts that are currently used have porcine and bovine origins, because of their similarity to the human bone regarding chemical composition (mainly carbonated hydroxyapatite and Type I collagen) and structure. Also, the interest in natural coral exoskeletons has been increasing. Synthetic grafts are the other alternatives to the BGMs. The advantages of these materials include reduced morbidity of harvesting autogenous and/or allograft bone, increased availability, and decreased anesthetic/operative time and associated costs. Commercial materials differ in the tailoring of their size, form, osteoconductivity, osteoinductivity, and resorption kinetics. ${ }^{5}$ Despite the increase in the number of procedures that require bone grafts, there has not been an ideal bone graft substitute. ${ }^{6}$

Due to the radiopacity of graft materials, it is possible to radiologically detect the form and voids within the material. Enough radiopacity in order to be distinguished from the surrounding anatomic structures is a desirable property for dental graft materials as well as all biomaterials. A number of studies focusing on the radiopacity of dental materials including direct restorative materials, cavity liners, denture base materials, elastomeric impression materials, endodontic sealers, posts and retrograde materials, adhesive systems, etc., have been reported. ${ }^{7}$

As a general rule, densitometers are used for reading optical densities on radiographic films, in accordance with the recommendations of the American Dental Association. ${ }^{8}$ In the transmission densitometer, the obtained optical density is a logarithmic measure of the ratio of 
Comparative Evaluation of the Radiopacity of Bone Graft Materials

Table 1: Bone graft materials evaluated in this study and their detailed characteristics

\begin{tabular}{|c|c|c|c|}
\hline Materials & Manufacturer & Composition & Grain size \\
\hline Osteobiol Mp3 & Tecnoss, Italy & Cortico-cancellous porcine bone mix & $0.6-1 \mathrm{~mm}$ \\
\hline Osteobiol Gel 40 & Tecnoss, Italy & Cortico-cancellous porcine bone mix & $\leq 0.3 \mathrm{~mm}$ \\
\hline Osteobiol Putty & Tecnoss, Italy & Cortico-cancellous porcine bone mix & $\leq 0.3 \mathrm{~mm}$ \\
\hline Maxxeus & Community Tissue Services, Ohio, USA & Allograft, Cortico-cancellous & $0.5-1 \mathrm{~mm}$ \\
\hline Allogenix (Putty) & Biomet, Microfixation, Irvine, USA & Allograft contains porous ceramic granules & $0.5 \mathrm{~mm}$ \\
\hline K-Phate & Merries International Inc., Taiwan & $\begin{array}{l}\text { Constituted by an ideal mixture of biphasic calcium } \\
\text { phosphate ceramic, } 60 \% \text { hydroxyapatite and } 40 \% \\
\beta \text {-tricalcium phosphate }\end{array}$ & $0.5-1 \mathrm{~mm}$ \\
\hline Suprabone & BMT Calsis A.S, Ankara, Turkey & $\beta$-tricalcium phosphate & $1-2 \mathrm{~mm}$ \\
\hline Puros & Tutogen Medical GmbH, Germany & Allograft, Cortico-cancellous & $0.25-1 \mathrm{~mm}$ \\
\hline Raptos & $\begin{array}{l}\text { Community Tissue Services, Dayton, } \\
\text { USA }\end{array}$ & Allograft, Cortico-cancellous & $0.5-1 \mathrm{~mm}$ \\
\hline Poresorb & Lasak Ltd, Praha, Czech Republic & Ceramic based on $\left[\beta-\mathrm{Ca}_{3}\left(\mathrm{PO}_{4}\right)_{2}\right]$ & $0.3-0.6 \mathrm{~mm}$ \\
\hline Kasios Tcp & Kasios, ZI La Croix, Launaguet, France & $\beta$-tricalcium phosphate & $0.5-1 \mathrm{~mm}$ \\
\hline Mineross & Osteotech, Eatontown, USA & Allograft, Cortico-cancellous & $0.6-1.25 \mathrm{~mm}$ \\
\hline Bego Oss & $\begin{array}{l}\text { aap Biomaterials GmbH, Dieburg, } \\
\text { Germany }\end{array}$ & $\begin{array}{l}1 \mathrm{~cm}^{3} \text { ceramic consists of } 0.6-1.1 \mathrm{gm} \text { hydroxyapatite } \\
\text { (pentacalcium hydroxide trisphosphate) on average } \\
\text { depending on the porosity of the ceramic }\end{array}$ & $0.5-1 \mathrm{~mm}$ \\
\hline Grafton Dbm (Putty) & Osteotech, France & Demineralized human bone matrix & Not available \\
\hline 4Bone & MIS Implant Technologies Ltd., Israel & $\begin{array}{l}\text { Calcium phosphate ceramic consisting of } 60 \% \\
\text { hydroxyapatite and } 40 \% \text { beta-tricalcium phosphate }\end{array}$ & $0.5-1 \mathrm{~mm}$ \\
\hline
\end{tabular}

transmitted to incident light through the film image. ${ }^{9}$ Radiopacity is usually expressed in terms of aluminum thickness and many researchers use aluminum stepwedges to compare the radiopacity of restorative materials under typical radiographic conditions., 70

The aim of the present study is to detect the radiopacity of commercially available BGMs in cadavers' mandibles to mimic the in vivo conditions and compare them with each other and bone tissue.

\section{MATERIALS AND METHODS}

This study evaluated the radiopacity of 15 BGMs that are commercially available. Their specifications are given in Table 1. Of the BGMs tested, six materials were allografts, three materials were xenografts, and the remaining six were synthetic grafts. Eight BGMs' grain size was higher than $0.6 \mathrm{~mm}$ and 4 BGMs' grain size was lower than $0.6 \mathrm{~mm}$.

A $5 \times 10$ mm-sized cavity was prepared with implant drill in the cadaver mandible (Fig. 1). The BGMs were prepared according to manufacturer's instructions and placed into the cavity respectively. After each implementation, parallel technique was utilized using a dental X-ray machine (Evolution X 3000-2C, New Life Radiology Srl, Italy) at $70 \mathrm{kVp}$ and $8 \mathrm{~mA}$ for $0.2 \mathrm{~s}$ with a $20 \mathrm{~cm}$ film-target distance. Size 2, Kodak D-speed dental films (Eastman Kodak) with a 7-step stepwedge (from 1 to $7 \mathrm{~mm}$ ) were exposed (Fig. 2). Films were processed using an automatic processor (Extra-x Velopex, Medivance

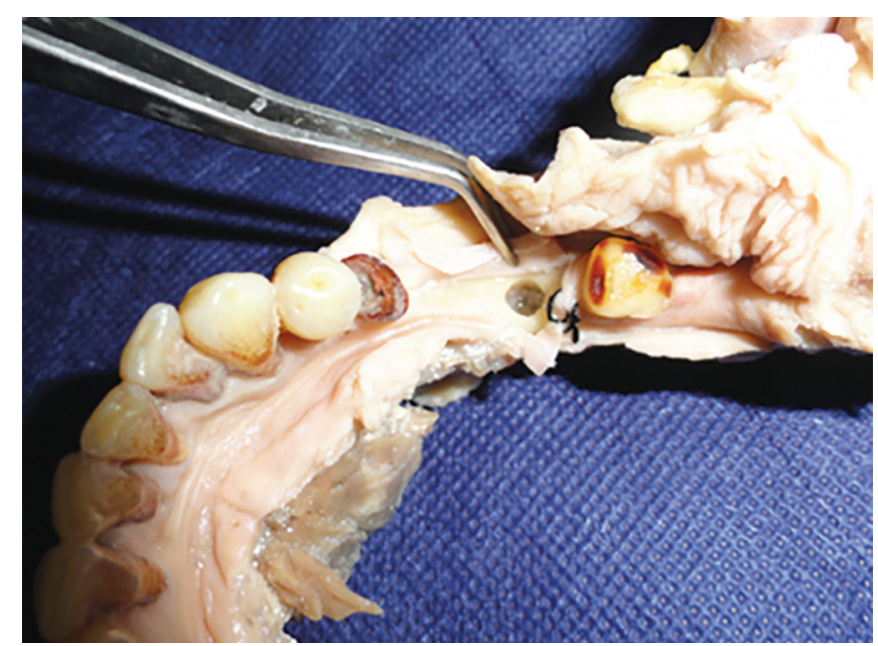

Fig. 1: $5 \times 10 \mathrm{~mm}$-sized cavity in cadaver's right mandible

Instruments Limited, London, England) with fresh solution (Hacettepe, Ankara, Turkey) mixed according to the manufacturer's instructions. For each material, three films were exposed and three readings were taken from each area and the mean was calculated. After exposure, the cavity was washed with distilled water and dried until all particles were removed. The radiographic densities of each step of the stepwedge, BGMs, bone, and enamel were measured using a densitometer (Densonorm 21 i, Phamed, Sulzbach, Germany) with a $1 \mathrm{~mm}$ aperture (Fig. 3). A graph of the optical density values for the entire stepwedge was plotted with the following equation: $\left(y=-0.664 \ln (x)+1.909, R^{2}=0.987\right)($ Graph 1) and used 

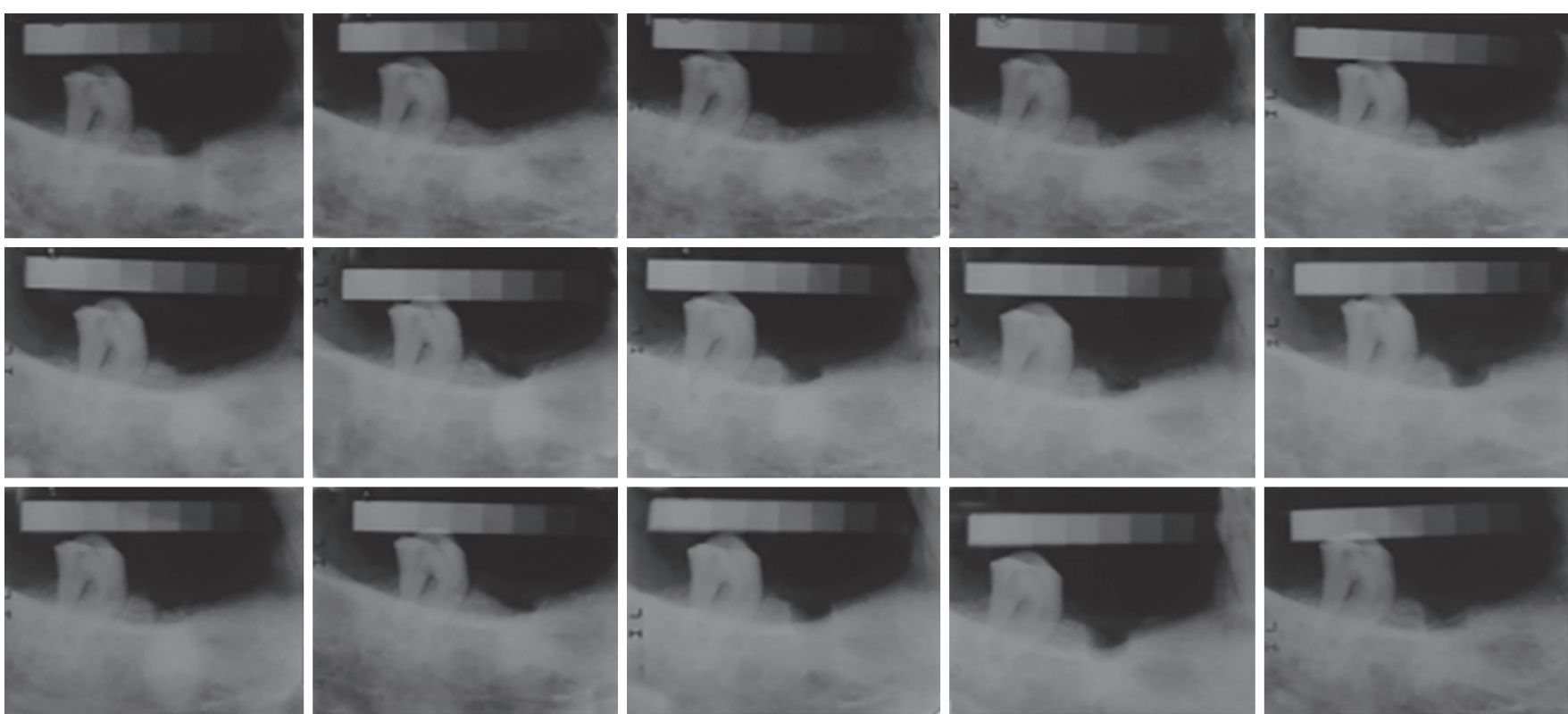

Fig. 2: Periapical radiographies of the cadaver's created cavity filled with BGMs, which were tested (upper line (from left to right): Grafton-Osteobiol Gel 40-Osteobiol Putty—Osteobiol MP3—Maxxeus middle line (from left to right): Kasios-Poresorb-4BoneRaptos-Puros; lower line (from left to right): Bego Oss-K-Phate-Allogenix-Suprabone-Mineross)

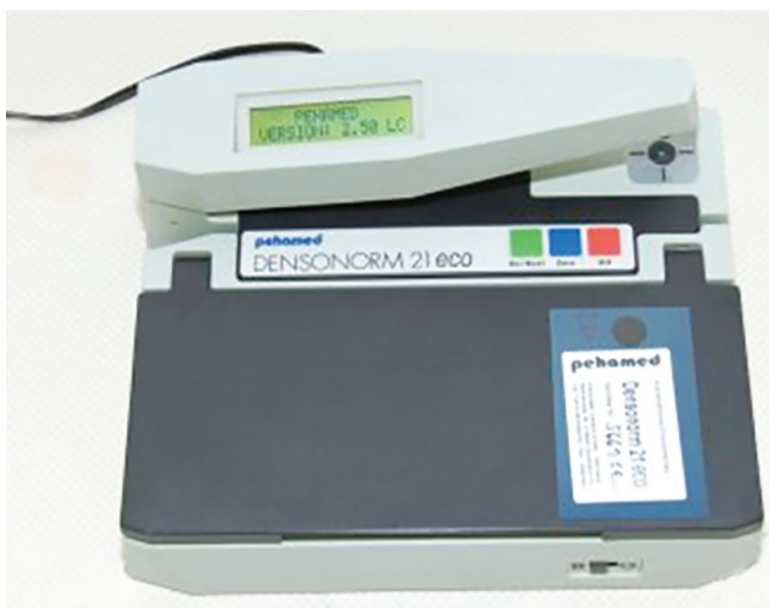

Fig. 3: Transmission densitometer used in the present study

to determine the aluminum thickness equivalent values of the materials. The mean radiopacity values for each of the materials tested were compared using ANOVA and post hoc Tukey honest significant difference tests $(\mathrm{p}<0.05)$.

\section{RESULTS}

The transmission densitometry optical density values of BGMs varied from 0.51 (the most radiopaque) to 0.71 (the most radiolucent). The aluminum equivalent thicknesses of the BGMs ranged from 2.13 to $2.35 \mathrm{~mm} \mathrm{Al}$ (Graph 2). Bego Oss (aap Biomaterials GmbH, Germany) exhibited the highest radiopacity of the materials tested, and Allogenix putty (Biomet, USA) exhibited the lowest (Table 2). The mandibular bone density was detected

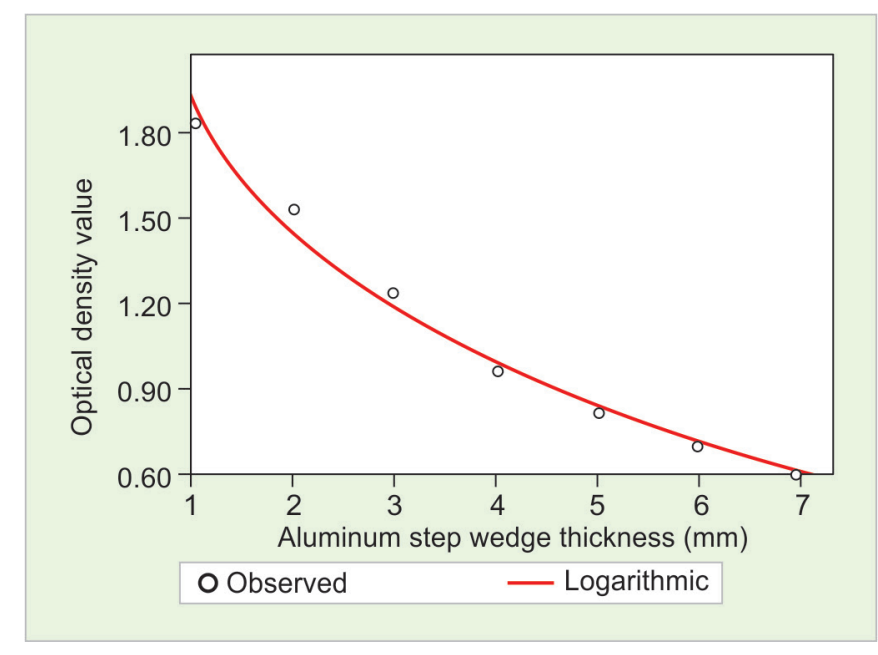

Graph 1: Optical density calibration curve

as $2.32 \mathrm{mmAl}$. No significant differences were found among Kasios (Kasios, France), Poresorb (Lasak, Check Republic), 4Bone (Mis, Israel), Bego Oss, and mandibular bone tissue $(p \geq 0.05)$ (Table 3$)$. The other BGMs exhibited less radiopacity than bone tissue with a marked significance $(p \leq 0.05)$.

\section{DISCUSSION}

In addition to BGMs' biological, physical, and mechanical properties, the radiopacity should be considered in selecting the most suitable material for specific clinical situations. There have been numerous histologic, histomorphometric, physicochemical experimental in vivo and in vitro studies in order to assess BGMs characteristics. 


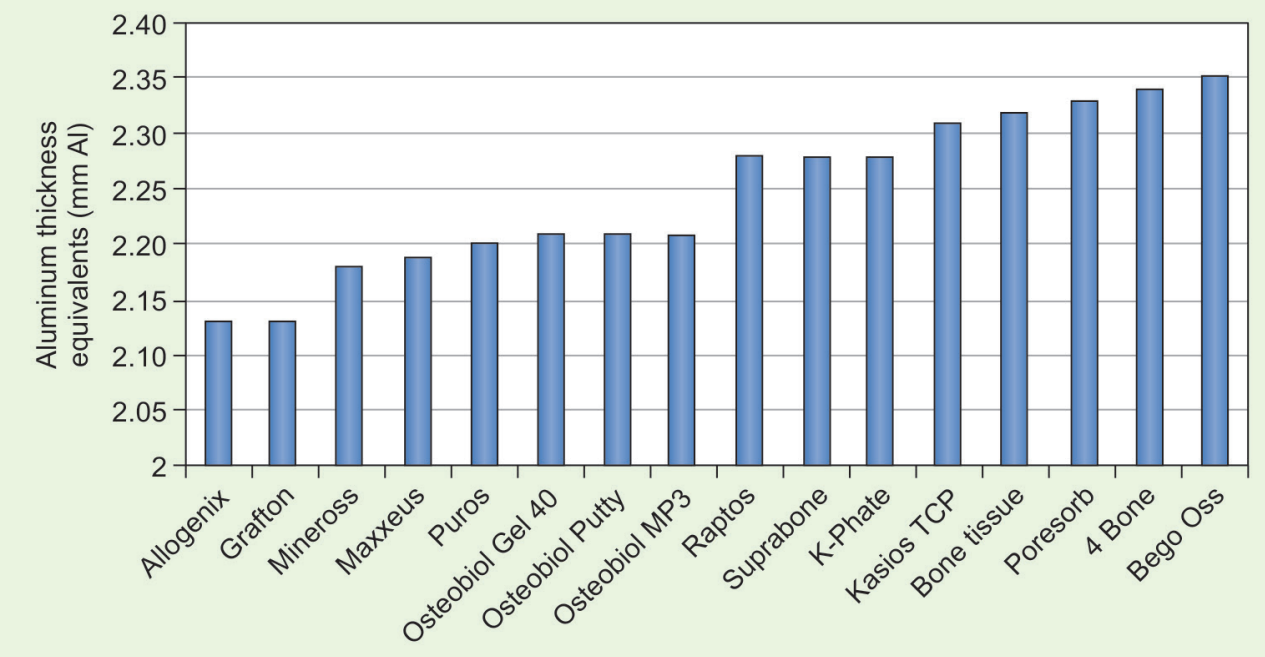

Graph 2: Aluminum equivalent values of tested BGMs and bone tissue

Also, radiographic evaluation of the BGMs has been carried out in various studies.

Verhoeven et $\mathrm{al}^{11}$ carried out the densitometric measurements on standardized oblique lateral cephalometric radiographs of the onlay grafts implemented to severe mandibular atrophy patients for a 1-year period. While there is a decrease in the density of the upper cortex of graft material, no significant change was observed in the upper spongeous part of the graft in the first 6-month period. An increase was detected in the radiographic density of the lower part of the spongeous bone in the second 6-month period.

Üngör ${ }^{3}$ evaluated the radiographic density of the two forms of DBM (putty and powder) on panoramic radiographs after maxillary sinus floor augmentation procedure and no significant differences were detected between the materials.

The increase of radiopacity was investigated by Ajeesh et al ${ }^{12}$ as a result of addition of nanoiron oxide to hydroxyapatite that has been widely used for a variety of bone filling and augmentation applications in dental and orthopedic field.

Bone mineral density measurements were also evaluated in numerous studies by dual-energy X-ray absorptiometry (DXA). ${ }^{13,14}$ The DXA is known as the most accurate clinical method for identifying those with low bone mineral density. 15,16

Some researchers compared the different donor bone types density with computed tomography (CT). Beckers et $\mathrm{al}^{17}$ showed that the iliac crest was the most consistently implantable donor site. In the study of Myoung et al, ${ }_{1}^{18}$ they evaluated the 120 bones from 20 Korean adults with CT. The cranial bone showed the highest cancellous bone density with statistical significance.
Table 2: Test results of BGMs used in the study

\begin{tabular}{llll}
\hline Tested materials & $\begin{array}{l}\text { Mean } \\
\text { optical } \\
\text { density }\end{array}$ & $\begin{array}{l}\text { Aluminum } \\
\text { equivalent } \\
\text { value }(\mathrm{mm} \mathrm{Al} \text { ) }\end{array}$ & $\begin{array}{l}\text { Standard } \\
\text { deviation }\end{array}$ \\
\hline Allogenix & 0.71 & 2.13 & \pm 0.006 \\
Grafton & 0.71 & 2.13 & \pm 0.005 \\
Mineross & 0.66 & 2.18 & \pm 0.004 \\
Maxxeus & 0.65 & 2.19 & \pm 0.008 \\
Puros & 0.64 & 2.20 & \pm 0.006 \\
Osteobiol Gel 40 & 0.63 & 2.21 & \pm 0.004 \\
Osteobiol Putty & 0.63 & 2.21 & \pm 0.004 \\
Osteobiol MP3 & 0.63 & 2.21 & \pm 0.004 \\
Raptos & 0.57 & 2.28 & \pm 0.01 \\
Suprabone & 0.57 & 2.28 & \pm 0.007 \\
K-Phate & 0.57 & 2.28 & \pm 0.004 \\
Kasios TCP & 0.54 & 2.31 & \pm 0.006 \\
Poresorb & 0.53 & 2.33 & \pm 0.006 \\
4Bone & 0.52 & 2.34 & \pm 0.006 \\
Bego Oss & 0.51 & 2.35 & \pm 0.006 \\
\hline
\end{tabular}

Dental materials are constantly reformulated and the desired goals are to make them radiopaque enough to enable a radiographical evaluation. Up to now, no published literature was found regarding the short-term radiopacity of BGMs after surgical procedure.

Pekkan et al ${ }^{19}$ investigated the radiopacity of six BGMs by comparing them with bovine mandibular cortical bone. Among the tested materials, Apatite-Wollastonite had the highest radiopacity with $3.681 \mathrm{~mm} \mathrm{Al}$ that was the nearest density to bovine mandibular cortical bone. The least radiopacity was exhibited by Bio Oss with $1.925 \mathrm{~mm}$ Al. The common material used in both studies was Kasios TCP. The equivalent thickness was found in the study of Pekkan et $\mathrm{al}^{7}$ and in the present study, $2.912 \mathrm{~mm} \mathrm{Al}$, $2.31 \mathrm{~mm} \mathrm{Al} \mathrm{respectively.} \mathrm{The} \mathrm{differences} \mathrm{were} \mathrm{attributed}$ 


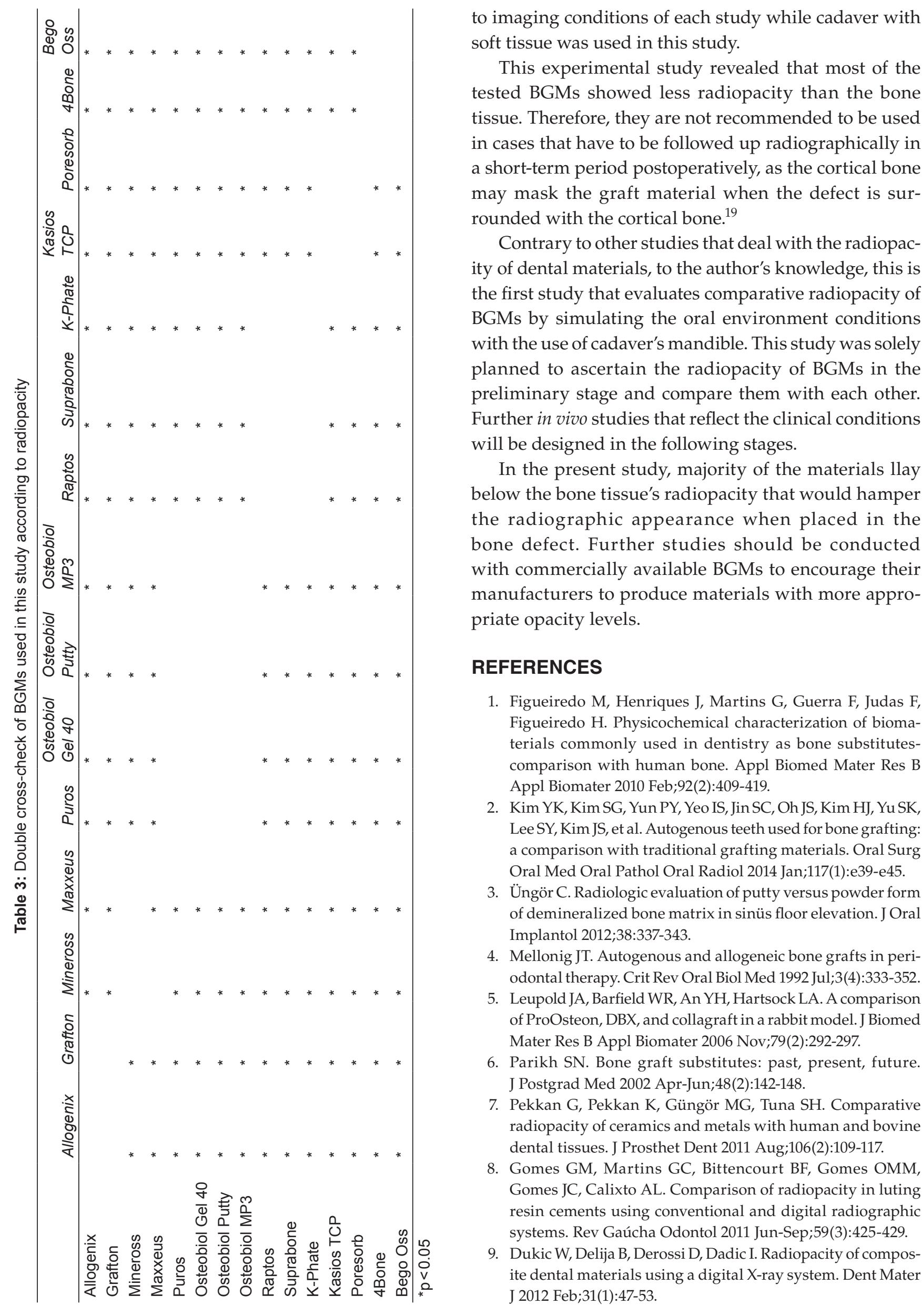


10. Öztas B, Kursun S, Dinc G, Kamburoglu K. Radiopacity evaluation of composite restorative resins and bonding agents using digital and film x-ray systems. Eur J Dent 2012 Apr;6(2):115-122.

11. Verhoeven JW, Ruijter J, Cune MS, Terlou M, Zoon M. Onlay grafts in combination with endosseous implants in severe mandibular atrophy: one year results of a prospective, quantitative radiological study. Clin Oral Impl Res 2000 Dec;11(6):583-594.

12. Ajeesh M, Francis BF, Annie J, Harikrishna Varma PR. Nano iron oxide-hydroxyapatite composite ceramics with enhanced radiopacity. J Mater Sci Mater Med 2010 May;21(5):1427-1434.

13. Ay S, Gursoy UK, Erselcan T, Marakoglu I. Assessment of mandibular bone mineral density in patients with type 2 diabetes mellitus. Dentomaxillofac Radiol 2005 Nov;34(6):327-331.

14. Knezović-Ziatarić D, Celebić A. Mandibular bone mineral density changes in complete and removable partial denture wearers: a 6-month follow-up study. Int J Prosthodont 2003 Nov-Dec;16(6):661-665.
15. Koh KJ, Park HN, Kim KA. Prediction of age-related osteoporosis using fractal analysis on panoramic radiographs. Imaging Sci Dent 2012 Dec;42(4):231-235.

16. Takahashi O, Yoshihara A, Nakamura K, Miyazaki H. Association between periodontitis and systemic bone mineral density in Japanese community-dwelling postmenopausal women. J Dent 2012 Apr;40(4):304-311.

17. Beckers A, Schenck C, Klesper B, Koebke J. Comparative densitometric study of iliac crest and scapula bone in relation to osseous integrated dental implants in microvascular mandibular reconstruction. J Craniomaxillofac Surg 1998 Apr;26(2):75-83.

18. Myoung H, Kim YY, Heo MS, Lee SS, Choi SC, Kim MJ. Comparative radiologic study of bone density and cortical thickness of donor bone used in mandibular reconstruction. Oral Surg Oral Med Oral Pathol Oral Radiol Endod 2001 Jul;92(1):23-29.

19. Pekkan G, Aktas A, Pekkan K. Comparative radiopacity of bone graft materials. J Craniomaxillofac Surg 2012 Jan; 40(1):e1-e4. 